\title{
¿La constancia de posesión y/o una licencia de construcción justifican la posesión y por ende no deviene en precario?
}

\author{
Does proof of possession and / or a construction \\ license justify possession and therefore does \\ not become precarious?
}

Dr. Juan Abelardo Villanueva Alarcón, Mgtr.

Investigador Jurídico, UNMSM y Villanueva Abogados

Artículo Original (Investigación)

RFJ, No. 3, 2018, pp. 297-319, ISSN 2588-0837

RESUMEN: el presente artículo analiza si algunos documentos, como una constancia de posesión, o una licencia de construcción justificarían la posesión de un inmueble y por ende si ello es conforme a la doctrina jurisprudencial y a los supuestos de ocupación precaria, establecidos en el IV Pleno Casatorio Civil, cuya aplicación es de obligatorio cumplimiento por parte de los órganos jurisdiccionales, o por el contrario, se está realizando un apartamiento de doctrina jurisprudencial y si esta se encuentra plenamente justificada y motivada.

PALABRAS CLAVES: posesión precaria, supuestos de ocupación precaria, IV Pleno Casatorio Civil, restitución, demanda.

ABSTRACT: the present article analyzes if some documents, such as a proof of possession, or a construction license would justify the possession of a property and therefore if it is in accordance with the jurisprudential doctrine and the precarious occupation, established in the IV Plenary Civil Casatorio, whose application is of obligatory fulfillment on the part of the jurisdictional organs, or on the contrary, a separation of jurisprudential doctrine is being made and if this is fully justified and motivated.

KEY WORDS: precarious possession, precarious occupation cases, IV Civil Casatorio Plenary, restitution, demand. 


\section{INTRODUCCIÓN}

Durante muchos años ha existido una carencia de predictibilidad sobre la aplicación correcta y uniforme de diversos institutos jurídicos a los casos que se venían ventilando ante el Poder Judicial, dicha carencia y sobre todo las resoluciones oscilantes han generado arduos debates por diversos sectores doctrinarios, de la cual tampoco podían estar ajenos los operadores jurídicos, sobre todo los órganos jurisdiccionales, ya que en ellos recaía el rol protagónico de dichas resoluciones y por ende eran participes activos en la problemática que ello generaba, claro que no de manera positiva, pues su accionar se reflejaba en la diversa jurisprudencia contradictoria e incluso las mismas eran emitidas en tiempos mínimos, por lo que, lo único que conducía era generar una inseguridad jurídica, aunado a una situación de inestabilidad e incertidumbre de poder saber cómo podría ser el resultado final de una determinada litis, y ello debido a que los pronunciamientos judiciales eran tan disimiles y contradictorios. Bajo dicha coyuntura es que hace unos años atrás se ha dado inicio a los plenos casatorios civiles por parte de la Corte Suprema de Justicia, los cuales justamente han tenido como misión fundamental el de unificar criterios en la emisión de resoluciones judiciales ${ }^{290}$ para que estos generen predictibilidad y sobre todo evitar mayores resoluciones contradictorias y oscilantes. Uno de los plenos jurisdiccionales es justamente al IV Pleno Casatorio Civil, emitido a raíz de la Casación No 2195-2011-Ucayali, del 29 de diciembre del 2011291, el cual versa sobre la posesión precaria, tema de por sí que ha desatado diversas posiciones y polémicas en nuestra doctrina nacional, pero que luego de haber sido objeto de un pleno casatorio civil, lleva a reflexionar e indagar cual ha sido el impacto de dicho precedente en los procesos judiciales en trámite, y sobre todo cómo es que viene siendo aplicando por los operadores jurisdiccionales, claro está, si es que se viene observando, conforme se va analizar en el presente trabajo.

290 La unificación de la jurisprudencia también es una de las finalidades que le ha impregnado el legislador al recurso de casación, conforme se observa en el artículo $384^{\circ}$ del Código Procesal Civil, el cual señala: el recurso de casación tiene por fines esenciales la correcta aplicación e interpretación del derecho objetivo y la unificación de la jurisprudencia nacional por la Corte Suprema de Justicia. En los casos previstos en la Ley General de Arbitraje, el recurso de casación tiene por finalidad la revisión de las resoluciones de las Cortes Superiores, para una correcta aplicación de las causales de anulación del laudo arbitral y de las causales de reconocimiento y ejecución de laudos extranjeros.

291 Publicado en el diario oficial "El Peruano" el día 14 de agosto del 2013. 


\section{LA POSESIÓN PRECARIA EN EL IV PLENO CASATORIO}

Resulta relevante observar cuales han sido los criterios adoptados y los precedentes establecidos para que nos permita poder afirmar si estás vienen siendo observadas y aplicadas por los órganos jurisdiccionales, conforme es la finalidad del presente trabajo, en ese sentido, es que procederemos con realizar un breve comentario a lo resuelto por nuestra Corte Suprema a raíz de la Casación No 2195-2011-Ucayali, el cual versa sobre un proceso de ocupante precario, convocando para ello al IV Pleno Casatorio Civil.

\subsection{La interpretación, efectuada por el IV Pleno Casatorio, sobre el artículo 911 del Código Civil}

Como se puede observar esos son los supuestos antes indicados de posesión precaria que todo órgano jurisdiccional deben de tener en cuenta cuando tenga en trámite un proceso sobre dicha materia. Sin embargo, vamos a analizar cómo es que se llegan a dichas conclusiones, para ello se tiene que indicar que la Corte Suprema arriba a estas, a partir del análisis efectuado al artículo 911 del Código Civil, otorgándole una interpretación amplia a la figura del precario, a fin de que de dicha manera pueda encuadrar en todos los supuestos casuísticos que se venían dando sobre dicha figura jurídica en nuestra jurisprudencia nacional y con ello evitar mayores resultados contradictorios, para ello la Corte Suprema manifiesta que era necesario partir de una conceptualización de la figura del precario, y que esta sea de manera clara y uniforme, ya que así permitirá resolver todos los supuestos en los que se encuentre inmersa dicha figura jurídica, y con ello darle efectividad al derecho de la tutela jurisdiccional efectiva. Así, la Corte Suprema señala que (es) dentro de una concepción general y básica, que cuando dicho artículo (911 del C.C.) en análisis hace alusión a la carencia de título o fenecimiento del mismo, no se está refiriendo al documento que haga alusión exclusiva al título de propiedad, sino a cualquier acto jurídico o circunstancia que hayan expuesto, tanto la parte demandante, como la demanda, en el contenido de los fundamentos fácticos tanto de la pretensión, como de su contradicción y que le autorice a ejercer el pleno disfrute del derecho a la posesión (...) entendiéndose que el derecho en disputa no será la propiedad sino el derecho a poseer ${ }^{292}$. Para la Corte Suprema la carencia del título o fenecimiento del mismo, no debe de circunscribirse

292 Considerando $N^{\circ} 51$ de la Casación N² 2195-2011-Ucayali. 22-23 de 84. 
al documento que acredite la propiedad sobre el bien, sino debe de entenderse en sentido amplio, esto quiere decir que el concepto de título establecido en el artículo 911 del código civil, incluye a cualquier acto jurídico o incluso a cualquier "circunstancia" en el cual demuestre, ya sea por el demandante o por el demandado, una autorización a ejercer el disfrute del derecho a la posesión ${ }^{293}$. Incluso el referido término es cambiado o aclarado en los considerandos 54 y 55, cuando la Corte Suprema desarrolla los supuestos previstos por el artículo 911 del código civil, en donde señala que "queda claro que la figura del precario se va a presentar cuando se esté poseyendo sin título alguno, esto es, sin la presencia y acreditación de ningún acto o hecho que justifique el derecho de disfrute del derecho a poseer (...) en este primer caso, no necesariamente se requiere de la presencia de un acto jurídico que legitime la posesión del demandado, lo que no excluye también el caso aquel en que el uso del bien haya sido cedido a título gratuito, sin existir de por medio el pago de una renta. 55.- el segundo supuesto que contempla la norma es que el título de posesión que ostentaba el demandado haya fenecido, sin precisar los motivos del fenecimiento, por lo que resulta lógico concebir que dicha extinción se puede deber a diversas causas, tanto intrínsecas o extrínsecas al mismo acto o hecho, ajenas o no a la voluntad de las partes involucradas (...)”294. Sobre este último, se puede observar que la Corte Suprema manifiesta que un título resulta fenecido, cuando el acto o hecho jurídico se ha

293 Luisa Alberto Larreátegui Torres, manifiesta que se debe de equiparar el término "circunstancia" como "hecho jurídico", cuando analizando dicho considerando de la referida casación manifiesta: "Así pues, hoy, para nuestros Tribunales, titulo no vendría a ser solamente acto jurídico, sino cualquier circunstancia que justifique el derecho a poseer el bien. Ergo, es un hecho jurídico". Luisa Alberto Larreátegui Torres. ¿Es precario quien ha adquirido el inmueble por usucapión? A propósito del Cuarto Pleno Casatorio. En: Actualidad Jurídica N² 242- enero 2014. Editorial Gaceta Jurídica, Lima. 64. Sin embargo, y a sabiendas que la Corte Suprema ha optado por establecer un concepto amplio de precario, no solamente se debería equiparar el término "circunstancia" a los hechos jurídicos, sino también a los actos jurídicos en sentido estricto, como lo manifiesta en voto singular la Dra. Ana María Aranda Rodríguez, en su considerando 6.2 de la Casación N²195-2011-Ucayali. 49. También compartimos lo vertido por quien manifiesta que no se puede dejar de tener en cuenta que el título requerido por el artículo 911 del Código Civil, puede estar referido a la ley, entendido este como justificante de la posesión. Al respecto Julio Pozo Sánchez. ¿Una nueva lectura del artículo 911 y la posesión precaria? Sobre el denominada "ausencia absoluta de circunstancias que justifiquen la posesión” en la jurisprudencia de la Corte Suprema. En: Debate Jurisprudencial. Editorial Motivensa, Lima, 2008.

294 Considerando $N^{\circ} 54$ y 55 de la Casación $N^{\circ}$ 2195-2011-Ucayali. 23-24 de 84. 
extinto por causas intrínsecas al acto o extrínsecas del mismo, lo cual nos lleva a manifestar que la extinción al cual hace referencia puede obedecer a una ineficacia estructural del negocio jurídico (nulidad o anulabilidad), o por una ineficacia funcional (resolución o rescisión).

\subsection{La regla interpretativa prevista para los artículos 585 y 586 del Código Procesal Civil}

Otra de las reglas establecidas por la Corte Suprema en el pleno en mención, ha sido indicar la forma de cómo se debe de interpretar el artículo 585 del Código Procesal Civil295, para lo cual la Corte Suprema parte manifestando que la interpretación realizada debe de ser concordada con los criterios que han venido estableciendo en dicho precedente vinculante, es decir que la referida norma procesal resulte aplicable a los tipos de causales de desalojo previstos por la referida Corte, bajo dicha premisa se indica que el primer párrafo de la referida norma procesal, en la cual hace alusión al término "restitución" del bien, manifiestan que debe de entenderse dicho termino como la "entrega" de la posesión que protege el artículo 911 del Código Civil, ya que con dicho criterio interpretativo se garantizaría a todo sujeto que le corresponde el derecho de ejercer el disfrute del bien, al margen que el derecho de propiedad se encuentre dilucidado o no, ya que al ser un proceso sumarísimo se podrá analizar si existe el derecho de restitución del mismo ${ }^{296}$. Es decir, el término "restitución" debe de entenderse en sentido amplio y genérico, y para justificar ello, complementan lo manifestado con la legitimidad activa y pasiva prevista en el artículo 586 del Código Procesal Civil, sobre el primero debe de comprender no solo al propietario, sino también al administrador y a todo aquel que considere tener derecho a la restitución de un bien, en

\section{Artículo 585.- Procedimiento}

La restitución de un predio se tramita con arreglo a lo dispuesto para el proceso sumarísimo y las precisiones indicadas en este Subcapítulo.

Procede a decisión del demandante, el acumular la pretensión de pago de arriendo cuando el desalojo se fundamenta en dicha causal. Si no opta por la acumulación, el demandante podrá hacer efectivo el cobro de los arriendos en el proceso ejecutivo de acuerdo con su naturaleza.

Cuando el demandante opte por la acumulación del pago de arriendos al desalojo, queda exceptuado el requisito previsto en el inciso 3) del artículo 85 de este Código. (Subrayado nuestro)

296 Considerando $N^{\circ} 57$ de la Casación N² 2195-2011-Ucayali. 24 de 84. 
tanto sobre la legitimación para obrar pasiva recae sobre todo aquel que ocupa el bien sin acreditar su derecho a permanecer en el disfrute de la posesión inmediata o que, en todo caso, en la realidad se han producido la desaparición de los actos o hechos jurídicamente regulados y protegidos, generando como efecto la pérdida del derecho a poseer ${ }^{297}$. Sobre este último, consideramos que se ha debido entender como legitimidad pasiva a todo aquel que se encuentre en posesión del bien, ya que la carencia de acreditación sobre el mismo o la desaparición del hecho o acto que antes justificaba su posesión es justamente la que será analizada por el Juzgador al momento de resolver, por lo cual se ha debido establecer que dicha legitimación recae únicamente sobre la persona que tiene la posesión directa e inmediata del bien, sin tener que entrar en detalle o describir las circunstancias de como dicha posesión se encuentra en cabeza de dicha parte ${ }^{298}$, ya que habiendo acogido un concepto amplio del precario. Del concepto de precario establecido por la Corte Suprema, se observa que existe una mayor generalidad en sus supuestos, y ello es establecido con la finalidad de poner fin a la diversa y hasta caótica jurisprudencia existente, que incluso podría señalarse que ha sido cuasi equiparado con el concepto de posesión ilegitima prevista en el Código Civil Argentino.

En efecto, nadie duda de que todos los supuestos previstos para la posesión precaria deben de ser regulados y se debe de tener en cuenta para solucionar el conflicto de intereses que se haya generado al respecto, ya que en caso de materializarse deben estar sujetos a tutela por la parte que tiene derecho sobre ella, pero un sector de la doctrina nacional manifiesta que no necesariamente implica a que dicha tutela o la

297 Considerando $N^{\circ} 60$ de la Casación N²195-2011-Ucayali. 25 de 84.

298 Sin embargo, se debe tener en cuenta que la referida norma procesal (art. 586 CPC) ha establecido que el sujeto pasivo del desalojo no solo es el precario, sino también en arrendatario o subarrendatario. Al respecto Pasco señala: "Cuando el legislador procesal señaló que procedía el desalojo contra el arrendatario y el subarrendatario, pensó en todos aquellos casos en los que el plazo de duración del contrato ha llegado a su fin y el pedido de devolución del bien por parte del arrendador no obtuvo una respuesta positiva por parte del arrendatario. Ahora, si la norma procesal distingue al precario del arrendatario, como sujetos pasivos del desalojo, entonces no podemos concebir al arrendatario con título fenecido como un poseedor precario. Lo contrario nos llevaría a concluir que el artículo $586^{\circ} \mathrm{CPC}$ incurre en una redundancia (a pesar de lo cual la norma no perdería operatividad, porque de todos modos procedería el desalojo)”. Alan Pasco Arauco. Sobre la posesión precaria, el desalojo y los intolerantes. 
solución del conflicto generado por dicho tipo de posesión tenga que ser resuelta vía proceso de desalojo, ya que dicho proceso es uno sumarísimo, conforme se encuentra previsto por nuestro Código Procesal Civil.

\section{DE LA APLICACIÓN DEL IV PLENO CASATORIO (Un caso ejemplificativo)}

Luego de haber hecho un somero análisis de lo previsto por la Corte Suprema en el IV Pleno Casatorio Civil, corresponde verificar si dichos criterios han sido aplicados por parte de los operadores jurisdiccionales, es decir, corresponde analizar la vigencia de estos precedentes en los procesos judiciales que versen sobre desalojo por ocupante precario ${ }^{299}$. Así, en el presente trabajo vamos analizar un caso sobre un proceso de desalojo donde justamente la parte demandante manifiesta que ha adquirido el derecho de propiedad sobre el inmueble materia sub Litis, en la cual indica que la demandada sin título alguno que lo amerite viene poseyendo dicho bien de su propiedad, para lo cual adjunta una escritura pública del año 2012, la cual contiene un contrato de compraventa y posteriormente -luego de iniciado el proceso- acreditan que dicho derecho de propiedad ha sido inscrito en la partida electrónica del inmueble. En la contestación de la demanda efectuada, la parte demandada contradice dicha acción y manifiesta que efectivamente tiene la posesión del bien, pero no es a título de ocupante precario, si no que la viene ocupando desde el año 1995 como propietaria legitima, por haberlo adquirido mediante contrato de compraventa en dicha fecha.

Luego de llevado acabo la audiencia única donde se desestimaron las excepciones deducidas por la parte demandada, respecto a la falta de legitimidad para obrar del demandante, el Juez emite sentencia, y dentro del análisis al caso concreto, en su considerando tercero manifiesta que el referido inmueble ha sido objeto materia de transferencia por parte del anterior titular registral a favor del demandante, asimismo, manifiesta que en el año 2011 el referido inmueble ha sido materia de una independización registral de su partida matriz, y es a raíz de dicha independización que se le adjudicó el inmueble materia sub litis a la transferente del demandante, quien posteriormente

299 Es importante reiterar que el precedente judicial vincula a todos los órganos jurisdiccionales de la República, por lo cual su observancia es necesaria, conforme se encuentra previsto por el artículo $400^{\circ}$ del C.P.C. 
le transfiere el bien a este, por lo cual el Juzgado concluye en dicho considerando tercero que efectivamente ha quedado acreditado el derecho de propiedad del demandante.

Sin embargo, y en el considerando cuarto, el Juzgado procede con hacer un análisis de la figura del precario, previsto en el artículo 911 del Código Civil, para lo cual manifiesta que efectivamente el poseedor precario es el que ejerce sin título alguno o cuando el que tenía ha fenecido, pero inmediatamente después hace una salvedad y señala que en el caso de autos "(...) la parte demandada con el mérito de la Constancia de Posesión $N^{\circ}$ 174-2012-SGPUC-GDU-MSS, expedida por el por la Gerencia de Desarrollo Urbano Subgerencia de Planeamiento Urbano y Catastro de la Municipalidad de Santiago de Surco obrante a fojas setenta y ocho y la Constancia de Posesión expedida por la Asociación Junta de Propietarios de la Urbanización Santa Modesta del Distrito de Santiago de Surco obrante a fojas ochenta y ocho acredita que el predio materia de litis está constituido por una vivienda unifamiliar de un piso y que su persona se encuentra en posesión del mismo el cual tiene un área de $133.53 \mathrm{~m} 2$, y que constituye una Vivienda Unifamiliar, hecho que se corrobora además con el mérito de las documentaciones obrantes de fojas setenta y nueve a fojas noventa y dos, que acreditan de que su persona ha pagado los tributos correspondientes por el inmueble ante la Municipalidad distrital de Santiago de Surco, así como que dicho inmueble cuenta con los servicios correspondientes de agua y luz emitidos a nombre de le emplazada y con la Licencia de Obra expedida mediante Resolución $N^{\circ}$ 2023-2006-SGLHU-GDU-MSS a nombre de la emplazada de fecha de expedición 16 de octubre del 2006 y de expiración de fecha 16 de octubre del 2009 que a la misma se le autorizo a efectuar una construcción de tres pisos más azotea con un área autorizada de 317.48 m2 en la Manzana B Lote 58 Vía San Miguel del AAHH Santa Modesta del referido distrito; que siendo ello así y habiendo la persona de la emplazada probado debidamente ser propietaria de la construcción efectuada sobre el terreno de propiedad de la parte demandante y sobre el cual existe una vivienda unifamiliar con uso de casa habitación es evidente de que su persona no puede tener la condición de precaria del mismo, puesto de que al ser propietaria de la construcción edificada sobre el bien sub. litis, es evidente de que cuenta con debido título para ocupar el inmueble. por lo que la demanda no puede ampararse; que la demás prueba actuada y no glosada no logra modificar los considerandos precedentes, por cuyas razones y en aplicación del artículo $200^{\circ}$ del Código Procesal Civil FALLO: declarando INFUNDADA la demanda por ocupación precaria (...); con costas y costos.-"(sic) (Subrayado y negritas nuestro). 


\subsection{La carencia de motivación y de análisis sobre los títulos invo- cados por las partes para establecer si efectivamente nos encon- tramos ante un caso de posesión precaria}

Lo primero que resalta dicha sentencia es que habiendo el Juzgado dejado por sentado que en el presente caso nos encontramos ante una parte demandante quien manifiesta y acredita tener el derecho de propiedad inscrito en Los Registros Públicos, el cual lo ha adquirido de su anterior titular registral, quien a su vez se adjudicó dicho bien mediante una independización registral, ya que antes formaba parte de un área mayor, del cual era copropietaria. Sin embargo, dicha titularidad registral, o con mejor precisión, el tracto registral respecto de dicho bien, ha debido ser establecido con las fechas en las cuales se originaron e inscribieron, ello hubiese sido importante para poder determinar los actos y quienes han suscrito sobre los mismos, para también establecer la legitimidad del derecho transferido respecto de dicho demandante, pero lamentablemente en la sentencia objeto de análisis no se indica ello, ni menos aún se precisa si dichos asientos registrales eran previos o posteriores al año 1995, para poder establecer con exactitud si la demandada, quien también manifiesta haber adquirido el bien mediante minuta de compraventa lo ha efectuado mediante una adquisición, anterior o posterior a la publicidad registral ${ }^{300}$ invocada por su demandante y el de sus transferentes, o si nos encontramos ante una adquisición a non domino, de ser así, incluso, poder establecer si realmente ha existido un accionar de buena o mala fe, ya que conforme se indicó, en caso sea una adquisición a un tercero, no se podría dejar de lado la publicidad registral, conforme se encuentra previsto en el artículo $2012^{\circ}$ del Código Civil ${ }^{301}$, $\mathrm{o}$, contrariamente a todo ello si nos encontramos ante dos adquisiciones efectuadas por un solo transferente, y si de ser estaríamos ante un caso en el cual uno de estos adquirentes ha procedido con escriturar e inscribir registralmente su derecho de propiedad (demandante). Toda esta serie y cúmulos de posibilidades se hubiesen descartado si el Juzgado hubiese establecido con claridad los títulos invocados y el contenido de

300 Situación de suma importancia, ya que por virtud de la publicidad registral, prevista en el artículo $2012^{\circ}$ del Código Civil, se aplica la presunción iure et de iure, de que todos tienen conocimiento de los asientos registrales, en el presente caso si la demandada al momento de la suscripción de su minuta no estaba inscrito el derecho de propiedad de su transferente, sino estaba inscrito a nombre de un tercero, no podría invocar un accionar de buena fe.

301 Artículo 2012.- Se presume, sin admitirse prueba en contrario, que toda persona tiene conocimiento del contenido de las inscripciones. 
estos, es decir, si el Juzgador hubiese efectuado un adecuado análisis de los títulos invocados por las partes, para establecer si nos encontramos efectivamente ante la figura del precario, ya que de los supuestos antes indicados se puede observar que las posibilidades de establecer un conflicto de intereses entre las partes es variada, y ello se hubiera dilucidado mediante una valoración conjunta de las pruebas aportadas por ambas partes, lo cual lamentablemente no se realizó en la sentencia en cuestión.

Dicha omisión se agrava con la argumentación y motivación emitida por parte del Juzgado, quien en la parte expositiva de los actos procesales llevados a cabo en el proceso, manifiesta únicamente que la parte demandada ha negado tener la situación de precario porque manifestó haber adquirido dicho bien en el año 1995, pero no existe mayor referencia ni análisis sobre la misma. Incluso, en la misma sentencia no se hace alusión en ningún otro extremo, es más no existe mayor análisis sobre el título invocado por dicha parte demandada, solamente se hace referencia en la parte expositiva para indicar que ha sido invocada por la demandada para negar que devenga en ocupante precario. Como se puede observar la carencia de motivación en dicha sentencia es evidente, lo cual atenta contra el debido proceso, ya que era de esperarse que siendo invocada la figura del precario, previsto por el artículo 911 del Código Civil, se ha debido analizar si el título invocado por dicha parte demandada se subsume en el supuesto de hecho previsto en la referida norma civil, pero no se han analizado los títulos en juego para poder establecer si nos encontramos ante una posesión precaria, lo cual evidencia una clara contravención a principios jurisdiccionales previstos por el artículo 139 de nuestra Constitución ${ }^{302}$, a lo expuesto se tiene que añadir que dicha resolución no muestra observancia al precedente vinculante establecido en el IV Pleno Casatorio.

302 Artículo $139^{\circ}$. Son principios y derechos de la función jurisdiccional:

(...)

3. La observancia del debido proceso y la tutela jurisdiccional.

Ninguna persona puede ser desviada de la jurisdicción predeterminada por la ley, ni sometida a procedimiento distinto de los previamente establecidos, ni juzgada por órganos jurisdiccionales de excepción ni por comisiones especiales creadas al efecto, cualquiera sea su denominación.

(...)

5. La motivación escrita de las resoluciones judiciales en todas las instancias, excepto los decretos de mero trámite, con mención expresa de la ley aplicable y de los fundamentos de hecho en que se sustentan. 
Efectivamente, el IV Pleno Casatorio Civil, ha establecido claramente que en este tipo de procesos el debate se debe centrar en la carencia del título o el fenecimiento del mismo, y ello se tiene que establecer dentro del proceso bajo una adecuada valoración de las pruebas aportadas en el proceso que vislumbren quien tiene el derecho a poseer, expresamente en el considerando $\mathrm{N}^{\circ} 56$ la Corte Suprema ha establecido que "(...) la no existencia de un título o el fenecimiento del que se tenía -con el cual justificaba su posesión el demandado- se puede establecer como consecuencia de la valoración de las pruebas presentadas, de dicha valoración es que surge en el Juez la convicción de la no existencia de título o que el acto jurídico que lo originó contiene algún vicio que lo invalida, como es una nulidad manifiesta prevista por alguna de las causales del artículo $219^{\circ}$ del Código Civil, o en todo caso, cuando siendo válido el negocio jurídico, este ha dejado de surtir efectos por alguna causal de resolución o rescisión, pero sin que el juez del desalojo se encuentre autorizado para declarar la invalidez, nulidad, ineficacia, etc., de dicho acto jurídico, por cuanto ello corresponde al juez donde se discuta tal situación" ${ }^{303 .}$ En efecto, si el juzgado ha dejado sentado en su considerando tercero de la sentencia que luego de haber valorado los medios probatorios aportados por la parte demandante, y seguidamente manifiesta que ha quedado acreditado el derecho de propiedad sobre el bien de este, también ha debido de proceder con valorar el título referido por la parte demandada conjuntamente con las demás pruebas aportadas, y establecer si la misma justifica la posesión del bien, ya que si señala que el accionante es quien tiene el derecho de propiedad sobre el bien, ha debido de cumplir con su obligación de valorar la prueba principal aportada por la demandada y con ello establecer si la misma tiene derecho a poseer o no, ya que como el mismo precedente establece en su parte in fine de su considerando 51 [se debe entender] "que el derecho en disputa no será la propiedad sino el derecho a poseer" ${ }^{304}$. De lo expuesto se puede observar que dicho juzgador no ha incumplido con dicha observancia, es más no ha hecho referencia alguna al título invocado por dicha demandada, sino a otros documentos que serán analizados más adelante, lo cual evidencia la nula observancia y vinculación de los órganos jurisdiccionales a los precedentes establecidos por la Corte Suprema, lo cual no solo resulta sumamente preocupante, sino demuestra una contravención a las mismas y a las normas legales que las respaldan, justifican y obligan su observancia y cumplimiento, ya que si bien se han establecido plenos jurisdiccionales cuya finalidad ha

303 Considerando $N^{\circ} 56$ de la Casación $N^{\circ}$ 2195-2011-Ucayali. 24 de 84.

304 Considerando $N^{\circ} 51$ de la Casación $N^{\circ}$ 2195-2011-Ucayali. 23 de 84. 
sido el poder establecer criterios que permitan unificar las diversas y oscilantes resoluciones emitidas sobre una misma figura jurídica, y si bien la emisión de las mismas han sido objeto de diversas críticas, esta ha sido plasmada para que justamente se eviten mayores resoluciones contradictorias y se genere predictibilidad de todos los casos en los cuales se involucren los mismos institutos jurídicos, pero de nada sirve este tipo de iniciativas si los órganos jurisdiccionales van a inobservar y no aplicar los mismos, y no es que nos encontremos ante el supuesto excepcional de apartamiento de un precedente vinculante como establece el artículo 22 de la Ley Orgánica del Poder Judicial ${ }^{305}$, porque para ello previamente el Juzgador debería de cumplir con analizar el precedente vinculante que se pretende dejar de aplicar y por ende motivar adecuadamente las razones por los cuales dejan de lado dicho precedente para justificar los fundamentos propios. En el presente caso nos encontramos ante un incumplimiento del primer párrafo del referido artículo (22 del LOPJ), pues no solo se está incumpliendo con la obligación de aplicar los precedentes establecidos en los plenos casatorios de la Corte Suprema, sino no hay observancia mínima sobre estas, aun cuando uno no pueda estar de acuerdo con los mismos, estos han sido establecidos bajo una cierta finalidad, la cual se contraviene y ello ahonda la grave inestabilidad que podría generar sentencias como la analizada, ya que flaco favor le hace no solo por no aplicarla, sino por contravenirla.

\section{Artículo 22.- Carácter vinculante de la doctrina jurisprudencial}

Las Salas Especializadas de la Corte Suprema de Justicia de la República ordenan la publicación trimestral en el diario oficial "El Peruano" de las Ejecutorias que fijan principios jurisprudenciales que han de ser de obligatorio cumplimiento, en todas las instancias judiciales.

Estos principios deben ser invocados por los Magistrados de todas las instancias judiciales, cualquiera que sea su especialidad, como precedente de obligatorio cumplimiento. En caso que por excepción decidan apartarse de dicho criterio, están obligados a motivar adecuadamente su resolución dejando constancia del precedente obligatorio que desestiman y de los fundamentos que invocan.

Los fallos de la Corte Suprema de Justicia de la República pueden excepcionalmente apartarse en sus resoluciones jurisdiccionales, de su propio criterio jurisprudencial, motivando debidamente su resolución, lo que debe hacer conocer mediante nuevas publicaciones, también en el diario oficial "El Peruano", en cuyo caso debe hacer mención expresa del precedente que deja de ser obligatorio por el nuevo y de los fundamentos que invocan. (subrayado mío). 


\section{2. ¿̇La constancia de posesión y/o la licencia de construcción son justificantes de la posesión, o descarta que uno devenga en precario?}

Pues bien, el Juzgador al inicio de su considerando cuarto hace referencia que la figura del precario, previsto en el artículo 911 del Código Civil, es la que se ejerce sin tener título alguno o cuando el que tenía ha fenecido, por lo cual uno mínimamente puede esperar que justamente se proceda con el análisis de dichos supuestos previsto por dicha norma, y ver su correlato con los títulos invocados por las partes, para que se proceda con verificar si alguno se subsume en la fattispecie de la norma en mención. En el presente caso, el título invocado por la demandada para justificar su posesión, manifiesta que lo hace como propietaria, ya que señala haber adquirido el referido inmueble mediante una minuta de compraventa del año 1995. Bajo dicho argumento, el Juzgado tenía la obligación de analizar el título invocado, tal como lo hizo con el demandante, donde arriba que efectivamente el derecho de propiedad sobre el inmueble recae en cabeza de dicha parte procesal. Sin embargo, no existe análisis alguno de parte del Juez sobre el título invocado por la demandada, es más en el considerando cuarto, cuando el Juzgado parte analizando los supuesto $s$ de precario, pero no hace referencia alguna al título en cuestión, es decir, no se ha cumplido con establecer si dicha demandada no tiene título o el que tenía ha fenecido.

Sin embargo, resultan llamativos los argumentos vertidos por el juzgador en dicho considerando cuarto de la sentencia, objeto de análisis, que si bien omite con referirse y merituar el título por el cual dicha demandada justifica su posesión, si procede con analizar los demás medios probatorios adjuntados por ésta, y no sólo ello, sino que son los referidos documentos los que invoca en su ratio decidendi indicando que los mismos son los que le van a generan convicción para establecer que dicha demandada no deviene en precario, ¿y cuáles son estos documentos?

Pues bien, el Juzgador manifiesta que la demandada ha adjuntado: i) Una constancia de posesión expedida por la Municipalidad; ii) Una constancia de posesión expedida por una Asociación; iii) Recibos de pago de los tributos ante la Municipalidad; iv) Una licencia de construcción expedida por la Municipalidad.

Cuando se refiere sobre las constancias de posesión adjuntadas por la demandada, el Juzgado manifiesta que "ello acredita que la deman- 
dada se encuentra en posesión del inmueble" (sic) materia sub. litis, lo cual nadie cuestiona, si estamos ante un proceso judicial de desalojo por ocupante precario, es justamente porque la parte demandada tiene la posesión directa e inmediata del bien, pero si se cuestiona que esta sea conforme a Ley, por ello es que se debió de analizar si dicha posesión es acorde con derecho, y ello se dilucida mediante la acreditación de un título que justifique dicha posesión, por lo cual la interrogante cae por si sola ¿̇dichas constancias de posesión son medios probatorios idóneos que justifiquen la posesión? Obviamente que no, si bien las municipalidades se encuentran facultadas para emitir certificados o constancias de posesión, son efectuadas para finalidades totalmente ajenas a la de pretender legitimar o justificar una posesión sobre un inmueble determinado; normalmente se expide para facilitar al acceso de servicios básicos, y estos se dan generalmente para posesiones informales, así basta ver lo regulado por el artículo 27 del Decreto Supremo $\mathrm{N}^{\circ}$ 017-2006-VIVIENDA ${ }^{306}$, por tanto pretender darle un mérito distinto al cual están destinados dichos documentos generaría una desnaturalización de estos, como lamentablemente parece que fue el fundamento del Juez, ya que el ejercicio de hecho sobre dicho bien que acredita dicha constancia en nada desbarata que sea acorde con Derecho, o que podría ser utilizado como el documento idóneo que justifica la posesión del inmueble. En efecto, el Juzgador no ha tomado en cuenta que una constancia de posesión no puede ser asimilada como un título que justifique la posesión del bien, o que legitime la posesión que detente el ocupante, y acá hacemos énfasis a la constancia de posesión emitida por una Municipalidad, no el de una asociación privada, de la cual tal vez la propia demandada podría formar parte. Alan Pasco, al respecto manifiesta que "el certificado de posesión únicamente acredita la posesión de facto, mas no constituye un título vigente que otorgue el derecho a poseer. Y como para que no queden dudas, el mismo certificado de posesión contiene la mención de no constituir reconocimiento alguno que afecte el derecho de propiedad de su titular ${ }^{307}$ ", y efecti-

306 Artículo 27.- Las municipalidades distritales en cuya jurisdicción se encuentre ubicada una posesión informal o la municipalidad provincial cuando se encuentre dentro de su Cercado, otorgarán a cada poseedor el Certificado o Constancia de Posesión para los fines del otorgamiento de la factibilidad de Servicios Básicos. (Subrayado nuestro).

307 Alan Pasco Arauco. La defensa del poseedor precario en el proceso de desalojo ¿El certificado de posesión constituye título que justifique la permanencia del bien? La Corte Suprema se reivindica. En: Revista Jurídica del Perú Nº 119, enero 2011. Normas Legales, Lima. 293. 
vamente dichas constancias son emitidas para finalidades totalmente distintas que la de justificar la posesión misma, su finalidad esencial es de acreditar una situación fáctica, la cual es la posesión del bien, sin adentrarse de si esta es conforme o no a Derecho, por ello que se limita a acreditar el mismo, y señalar expresamente que la emisión de dicho documento no genera reconocimiento de derecho alguno sobre la misma. Incluso llama la atención que la sentencia en cuestión haya tomado dicho documento como título justificante de la posesión, u otorgarle legitimidad a la persona que cuente con dichas constancias para manifestar que ello no lo hace devenir en precario, o que posee conforme a Ley, ya que incluso con anterioridad al IV Pleno Casatorio Civil, la Corte Suprema en diversas ocasiones se había pronunciado sobre las constancias de posesión emitidas por entidades municipales, negando que esta pueda generar vínculo alguno del poseedor y el surgimiento de un derecho a poseer.

Así, en la Casación $\mathrm{N}^{\circ} 221-2001-\mathrm{Ica}^{308}$, se señala "Los documentos presentados por el demandado, tales como recibos de autovalúo y copia simple del Certificado de Posesión, entre otros, constatan su conducción sobre el predio; pero no constituyen título que justifique su posesión", igualmente en la Casación $N^{\circ} 417-2009-$ Ica $^{309}$, la Corte Suprema expresamente se ha manifestado sobre el certificado de posesión indicando "Que el certificado de posesión número 347-2007-DS/a, expedido por la Municipalidad Distrital de Sunampe - Chincha que adjunta, no genera vinculo jurídico entre el recurrente y el demandante, que pueda justificar de alguna manera la posesión del inmueble, más aún, si adjunta copia simple, y del mismo se desprende que "no constituye reconocimiento alguno que afecte el derecho de su propiedad de su titular' (...)".

Otro de los documentos analizados por el Juzgador y que lo han llevado al convencimiento que la demandada no tiene una posesión precaria, es por la presentación de una licencia de construcción adjuntada a su contestación de demanda. Al respecto, el Juzgador manifiesta que

308 Extraído de: Héctor E. Lama More. La Posesión y la posesión precaria en el derecho civil peruano. El nuevo concepto del precario y la utilidad de su actual regulación en el Derecho Civil Peruano. 199.

309 Publicado en el diario oficial El Peruano el 30 de junio del 2010. Sobre un comentario a dicha casación. Alan Pasco Arauco. La defensa del poseedor precario en el proceso de desalojo $i^{E l}$ certificado de posesión constituye título que justifique la permanencia del bien? La Corte Suprema se reivindica. En: Revista Jurídica del Perú N 119, enero 2011. Normas Legales, Lima. 
habiendo obtenido dicha autorización o licencia para la edificación de tres pisos más una azotea sobre el bien, queda acreditado que dicha demandada es propietaria de la construcción, e incluso deja sentado que dicha construcción fue efectuada sobre el terreno de propiedad de la demandante y sobre la cual existe una vivienda unifamiliar con uso de casa habitación, por lo cual dicha situación lleva a concluir que ello evidencia de que dicha persona no puede tener la condición de precaria. Así, basta citar dicho extremo del considerando cuarto:

(...) con la Licencia de Obra expedida mediante Resolución $N^{\circ}$ 2023-2006-SGLHU-GDU-MSS a nombre de la emplazada de fecha de expedición 16 de octubre del 2006 y de expiración de fecha 16 de octubre del 2009 que a la misma se le autorizo a efectuar una construcción de tres pisos más azotea con un área autorizada de $317.48 \mathrm{~m} 2$ en la Manzana B Lote 58 Vía San Miguel del AAHH Santa Modesta del referido distrito; que siendo ello así y habiendo la persona de la emplazada probado debidamente ser propietaria de la construcción efectuada sobre el terreno de propiedad de la parte demandante y sobre el cual existe una vivienda unifamiliar con uso de casa habitación es evidente de que su persona no puede tener la condición de precaria del mismo, puesto de que al ser propietaria de la construcción edificada sobre el bien sublitis. es evidente de que cuenta con debido título para ocupar el inmueble, por lo que la demanda no puede ampararse. (Sic). (Subrayado mío).

Como se puede observar, el Juez no toma en cuenta que las licencias de construcción constituyen autorizaciones para la ejecución de obras o edificaciones, siempre que hayan cumplido con los requisitos que dicho otorgamiento genera, pero la emisión de la misma constituye únicamente un permiso para que se puedan realizar trabajos de construcción y/o edificación, mas no constituye prueba fehaciente que dicha edificación o construcción se haya efectuado o concluido.

Me explico, si bien obra en autos la emisión de una licencia de construcción, el juez ya dejó sentado que por la emisión de dicho documento, existe una edificación, y no solo ello también manifiesta que la misma es de propiedad de la demandada, aun cuando dicho supuesto no ha sido probado ni referido por la demandada. Lo más llamativo surge seguidamente, cuando el Juez refiere que dicha edificación es el fundamento que le permite manifestar que la demandada no deviene en precaria, ya que la edificación demuestra el "debido título" con el cual cuenta dicha parte para justificar su posesión, sin manifestar cómo es que dicha edificación viene a ser un título que justifique la 
posesión. Lamentablemente, dicho argumento no toma en cuenta que la emisión de licencias de construcción no conlleva a un pronunciamiento o reconocimiento acerca de la titularidad de derechos reales sobre el inmueble que se pretende edificar, conforme ahora lo establece el artículo $12^{\circ}$ de la Ley $\mathrm{N}^{\circ} 29090^{310}$, y conforme ya hemos indicado que las edificaciones o modificaciones que se hagan sobre el bien no justifican la posesión, ni pueden ser asimilados como un título.

Dicho criterio es sumamente peligroso, ya que podría ser la justificante para cualquier invasor que cuente con constancia de posesión (municipal o emitida por una asociación privada) o haya obtenido una licencia de construcción, la cual demostraría fehacientemente la existencia de una construcción, y será la justificante para que tenga derecho a poseer el bien. Dicho criterio demuestra una contradicción al supuesto de posesión precario previsto por el IV pleno Casatorio, el cual en su punto 5.5 establece: "Cuando el demandado afirme haber realizado edificaciones o modificaciones sobre el predio materia de desalojo - sea de buena o mala fe-no justifica que se declare la improcedencia de la demanda, bajo el sustento que previamente deben ser discutidos dichos derechos en otro proceso. Por el contrario, lo único que debe verificarse es si el demandante tiene derecho o no a disfrutar de la posesión que invoca, dejándose a salvo el derecho del demandado a reclamar en otro proceso lo que considere pertinente" ${ }^{311}$. Como se puede observar, la existencia de una edificación se toma como cierta a raíz del acervo probatorio adjuntado por la demandada para justificar su posesión, ya que se encontraba la licencia de construcción, a la cual el Juez la ha tomado como un supuesto justificante de la posesión, contraviniendo al IV Pleno Casatorio en el extremo que manifiesta que aun cuando existan edificaciones sobre el bien, ello no legitima el derecho a poseer, el Juez

310 LEY N 29090 - Ley de regulación de habilitaciones urbanas y de edificaciones.

Artículo 12.- Efectos El otorgamiento de la licencia de habilitación o de edificación determinará la adquisición de los derechos de construcción y desarrollo, ya sea habilitando o edificando, en los predios objeto de la misma, en los términos y condiciones expresados en la respectiva licencia. La expedición de las citadas licencias no conlleva pronunciamiento alguno acerca de la titularidad de derechos reales, sobre el inmueble o inmuebles, objeto de ella. Las licencias recaen sobre uno o más inmuebles y producen todos sus efectos, aun cuando sean enajenados. El régimen de aprobación automática, regulado en la presente Ley, no exime a las municipalidades del control posterior, el cual será regulado mediante el reglamento al que se hace referencia en el artículo 5 .

311 Casación N² 2195-2011-Ucayali. 32-33 de 84. 
ha manifestado que dicha edificación es la que justifica su posesión (debido título), y por ende no se configura como una posesión precaria, mostrando una trasgresión al precedente antes referido.

\section{3. ¿La edificación o mejoras en el predio objeto de desalojo otor- ga justo título y genera derecho a poseer el bien?}

Ya la Corte Suprema se ha pronunciado al respecto, y ha señalado expresamente en el punto V) del considerando 63 del IV Pleno Casatorio $^{312}$, el cual versa sobre los supuestos de posesión precaria, estableciendo que cuando en el proceso de desalojo se alegue la existencia de edificaciones o modificaciones en el inmueble materia de dicho proceso, no justificará que ante dicha circunstancia se tenga que supeditar o condicionar una previa discusión de dichos derechos en otro proceso y por ende declarar la improcedencia de la demanda. Contrariamente a ello, la Corte Suprema ha establecido doctrina jurisprudencial en el sentido que al encontrarse en dicho supuesto, el juez lo único que tiene que realizar es verificar si el demandante tiene derecho a disfrutar de la posesión que invoca, y verificado ello proceder con el desalojo, dejando a salvo el derecho de la demandada en caso de las edificaciones tomar las acciones que considere pertinenten. Sin embargo, en el presente caso el Juez ha dejado por sentado que el derecho de propiedad del bien recae en el demandante, pero justifica la posesión de la parte demandada bajo la existencia de una edificación,

312 Dicho punto versa sobre los supuestos de Posesión Precaria, en la cual se deja sentado lo siguiente:

63.- Al tener en cuenta lo dicho, siempre a título de numerus clausus, a continuación se plantea un conjunto de casos, que se han evidenciado como los más recurrentes en los procesos de desalojo que se tramitan en los diferentes órganos jurisdiccionales, y que configurarían supuestos de ocupación precaria:

(...)

V) En los casos en los que el demandado afirme haber realizado edificaciones o modificaciones sobre el predio materia de desalojo - sea de buena o mala fe-, no justifica que se declare la improcedencia de la demanda, bajo el sustento de que previamente deben ser discutidos dichos derechos en otro proceso. Por el contrario, lo único que debe de verificarse es si el demandante tiene derecho o no a disfrutar de la posesión que invoca, dejándose a salvo el derecho del demandado a reclamar, lo que considere pertinente, por causa de las edificaciones o modificaciones del predio, utilizando el procedimiento pertinente.

En: Considerando 63 de la Casación N² 2195-2011-Ucayali. 27. 
lo cual llevaría a entender como una concepción singular de título, pero no señala expresamente cual es la base legal de dicha justificación sobre dicha posesión, solamente declara que la titularidad de la edificación efectuada justifica la posesión sobre dicho bien, lo cual demuestra una clara contravención al precedente vinculante establecido en el IV Pleno Casatorio Civil.

Sobre este supuesto de edificaciones realizadas sobre el predio objeto de desalojo, el precedente vinculante resulta innovativo, y deja zanjado con dicha doctrina jurisprudencial todos los problemas que habían surgido en los proceso de desalojo en torno a la edificación realizada sobre el predio por el demandado, quien muchas veces invocada la titularidad de lo construido sobre el terreno de propiedad del demandante. Ya con anterioridad al IV Pleno Casatorio, La Corte Suprema en diversas ocasiones se ha pronunciado sobre la necesidad de acreditar primero la propiedad de la construcción por el demandante para que se proceda amparar la demanda de desalojo por ocupación precaria: Así, basta ver la Casación $N^{\circ}$ 2831-2003 La Libertad ${ }^{313}$, Casación $N^{\circ}$ 1763-2003 Lambayeque ${ }^{314}$, Casación $N^{\circ}$ 52-2004 Piura ${ }^{315}$. El argumento central emitido en dichas casaciones para declarar la improcedencia de las demandas de desalojo, estriba en que al pretenderse el desalojo tanto del terreno como de lo edificado sobre esta no se acreditaba una propiedad absoluta, es decir, tanto del terreno como de lo construido por parte del demandante, el cual resulta indispensable para que proceda el desalojo, pues resultaría física y jurídicamente imposible la restitución solo del terreno, por lo cual manifestaban que no resulta aplicable lo previsto por el artículo 911 del Código Civil, ya que no es posible el desalojo solo del terreno, por lo cual el demandado no tendría la calidad de poseedor precario por ser titular de lo construido

313 Publicado en el diario oficial El Peruano el 30 de mayo del 2005. Extraído de: Héctor E. Lama More. La Posesión y la posesión precaria en el derecho civil peruano. El nuevo concepto del precario y la utilidad de su actual regulación en el Derecho Civil Peruano. 190.

314 Publicado en el diario oficial El Peruano el 30 de junio del 2005. Extraído de: Héctor E. Lama More. La Posesión y la posesión precaria en el derecho civil peruano. El nuevo concepto del precario y la utilidad de su actual regulación en el Derecho Civil Peruano. 191.

315 Publicado en el diario oficial El Peruano el 30 de mayo del 2005. Extraído de: Héctor E. Lama More. La Posesión y la posesión precaria en el derecho civil peruano. El nuevo concepto del precario y la utilidad de su actual regulación en el Derecho Civil Peruano. 190. 
sobre el terreno. Como se puede observar, dicho criterio jurisprudencial causaba mayor detrimento en la situación jurídica del demandante con derecho a poseer, ya que se veía imposibilitado en poder ejercer dicha acción, pues previamente se tendría que dilucidarse el pago de la mejora o la edificación efectuada sobre el predio ${ }^{316}$, peor aun cuando la edificación o construcción era realizada por un poseedor quien construye de mala $\mathrm{fe}^{317}$, pues no tenía sentido establecer una condición o proceso previo para el ejercicio de la acción de desalojo, más en el supuesto previsto por el artículo 943 del Código Civil, cuando niega derecho alguno de reembolso a quien haya edificado en dicha condición (mala fe), por lo cual invocar la existencia de una construcción para no proceder con la acción de desalojo desnaturalizaba la figura del precario previsto en el artículo 911 del Código Civil, más si no existía base legal para manifestar que dicha construcción justificaba la posesión sobre el bien, motivo por el cual el IV Pleno Casatorio, ha manifestado que aun cuando exista construcción sobre el predio objeto de desalojo, ello no puede evidenciar o admitir como supuesto que genere el derecho a poseer sobre esta, en todo caso si existe derecho alguno de pago por las mejoras realizadas, ello no tiene por qué paralizar o suspender el ejercicio de dicha acción, pues la misma se podrá ventilar en el proceso pertinente.

De lo expuesto, surge la interrogante de saber si la edificación sobre el inmueble objeto de posesión es una justificante de la posesión. Al respecto, debemos tener presente que el artículo 911 del Código Civil ha establecido que en un proceso de desalojo por precario debe centrarse en analizar si la posesión del demandado es mediante un título que la justifique, y para ello, y de acuerdo con el caso concreto, se debe verificar cual es el título que porta el demandado, si es que lo

316 Un análisis efectuado sobre la edificación en terreno ajeno, el pago de mejoras, la accesión y su regulación en nuestra normatividad civil lo podemos encontrar en: Pasco Arauco, A. (2009). Edificación en terreno ajeno: entre la buena y la mala fe del constructor. ¿̨Convirtiendo las presunciones absolutas en presunciones iuris tantum? En: Actualidad Jurídica. Gaceta Jurídica. $N^{\circ}$ 183. Lima. También al respecto Pasco Arauco, A. (2010). Edificación de mala fe, mejoras y posesión ilegítima. En: Diálogo con la Jurisprudencia. Gaceta Jurídica. N 143 . Lima.

317 Hacemos referencia al supuesto en la cual existe publicidad registral del bien, en la cual se publicita la titularidad de un tercero con respecto a quien construye sobre el mismo, por lo que no se puede pretender negar desconocimiento de la existencia del mismo, por la presunción iure et de iure de conocimiento de los asientos registrales previsto en el artículo 2012 del Código Civil. 
porta, y este no ha fenecido, al tratarse de la existencia de una edificación se debe verificar si ello se puede oponer al título que porta e invoca la parte demandante. En ese sentido, $\mathrm{Pasco}^{318}$ menciona que las edificaciones en terreno ajeno, dan lugar a un tipo de accesión y constituyen un tipo de mejoras: precisando que son mejoras útiles sobre el bien, lo cual genera un derecho al reembolso del valor introducido sobre esta, por ello nuestro Código Civil ha establecido supuestos de la forma cómo el poseedor introdujo dichas mejoras para tener derecho a un reembolso, conforme consta de los artículo 941, 942 y 943 del Código Civil. Como se puede observar estos supuestos previstos en las normas aludidas generaran derechos potestativos al propietario del terreno o al constructor, según la buena o mala fe con la cual hayan actuado, pero de ninguna manera ello puede pretender equipararse como una justificante o genere una legitimidad en la posesión del bien, en otras palabras, el hecho que el poseedor inmediato haya edificado sobre el inmueble objeto de desalojo, de por sí no va demostrar que dicho constructor (poseedor) no deviene en precario.

Estos puntos y fundamentos no fueron debidamente analizados en la sentencia objeto de análisis, lo cual hace necesario un pronunciamiento crítico, pero no con la finalidad de denostar el trabajo que realizan los órganos jurisdiccionales, sino para coadyuvar a la correcta aplicación de las normas y precedentes emitidos para dichos procesos, y también para que en lo sucesivo se tenga mayor celo y contribuyan a la plena vigencia de la doctrina jurisprudencial que ha sido emitida para evitar resoluciones contradictorias sobre casos similares que se han ventilado, y de dicha forma se pueda impartir justicia de manera correcta y uniforme.

\section{CONCLUSIONES}

Nuestros órganos jurisdiccionales se encuentran obligados a tener presentes los precedentes vinculantes establecidos por nuestra Corte Suprema, ya que la finalidad de estos es generar unidad y predictibilidad de criterios en los fallos que versen sobre casos similares, y en la cual se encuentre inmerso el mismo instituto jurídico, ya que de esa manera se van a disminuir resoluciones oscilantes y contradictorias.

318 Pasco Arauco, A. (2010). Edificación de mala fe, mejoras y posesión ilegítima. En: Diálogo con la Jurisprudencia. Gaceta Jurídica. N 143 . Lima. 
En caso se proceda con el apartamiento de algún precedente tiene que realizar con sujeción a lo previsto por el artículo 22 de la LOPJ.

El IV Pleno Jurisdiccional Civil, ha efectuado una interpretación del artículo 911 del Código Civil, estableciendo en sentido amplio y genérico el concepto de precario, entendiéndose como precario a toda persona que ocupe un inmueble ajeno, sin pago de renta y sin título para ello, o cuando dicho título no genere ningún efecto de protección para quien lo ostente. La carencia de título o el fenecimiento del mismo no solo deben de entenderse respecto al documento, sino a cualquier acto jurídico que autorice a la demandada a ejercer la posesión del bien. El término de restitución previsto en el artículo $585^{\circ}$ del Código Procesal Civil debe de entenderse como entrega de la posesión que se encuentra tutelado por el artículo 911 del Código Civil.

En el presente caso el Juez no ha realizado un análisis de los títulos invocados por las partes del proceso en la sentencia en cuestión para que pueda declarar quien tiene el derecho a poseer el bien, contrariamente a ello se ha generado la convicción que no existe una posesión precaria por existir constancias de posesión y una licencia de construcción, los cuales son documentos no idóneos para justificar la posesión. Asimismo, la obtención de una licencia de edificación no puede generar la presunción que por la sola emisión del mismo se tiene que entender que existe una edificación o la conclusión de esta.

No se puede justificar la existencia de edificaciones o modificaciones sobre el predio objeto de desalojo, para que se declare la improcedencia del proceso, bajo el argumento que tiene que previamente dilucidarse el derecho en cuestión en otro proceso, contrariamente a ello, los órganos jurisdiccionales tienen que establecer si el demandante tiene derecho o no a disfrutar de la posesión del bien, es ante ello que el Pleno Jurisprudencial Casatorio ha establecido que dicho cuestionamiento en nada imposibilidad ni condiciona a que se resuelva el proceso de desalojo, dejando a salvo el derecho de la demandada que lo pueda hacer en el proceso que considere pertinente.

La edificación realizada sobre el predio del bien (ajeno), no puede ser considerado como título justificante sobre el predio, ni tampoco ser considerado como debido título o que legitima la posesión sobre esta, es decir, no puede ser entendida como la causa, razón, motivo para poseer, sino, y de acuerdo con el caso concreto, en cuanto haya mediado buena o mala fe, generará un derecho potestativo, como pue- 
de ser el reembolso de lo gastado para el constructor o hacerse propietario de esta construcción por el propietario del terreno, según las circunstancias que el caso concreto amerite.

\section{REFERENCIAS BIBLIOGRÁFICAS}

\section{Código Civil}

Ley General de Sociedades

Ley n 29090 - Ley de regulación de habilitaciones urbanas y de edificaciones

Lama More., H. E. (2005). La Posesión y la posesión precaria en el derecho civil peruano. En El nuevo concepto del precario y la utilidad de su actual regulación en el Derecho Civil Peruano, Lima: El Peruano

Pasco Arauco, A (2010). Edificación de mala fe, mejoras y posesión ilegítima, Diálogo con la Jurisprudencia- Gaceta Jurídica.

Pasco Arauco, A (2011). La defensa del poseedor precario en el proceso de desalojo ¿̇l certificado de posesión constituye título que justifique la permanencia del bien? La Corte Suprema se reivindica. Revista Jurídica del Perú, Nº 119, Lima: Normas Legales.

Recibido: 05/08/2017

Aprobado: 23/05/2018

Dr. Juan Abelardo Villanueva Alarcón: Abogado por la Universidad Nacional Mayor de San Marcos. Maestría en Derecho Civil y Comercial (LLM) por la misma casa de estudios.

Correo electrónico: J.abelardovillanueva@gmail.com 